\title{
SUBVERSION \\ Infinite Series and Transfinite Numbers in Borges's Fictions
}

\begin{abstract}
But can we not ask ourselves whether there do not exist, in the real universe, things which are non-algorithmizable, non-reducible, nonunifiable. . . . From that moment on, does the problem become, not to eject and repress uncertainty, randomness, disorder, antagonism outside its royal domain, but to seek dialogue with them?
\end{abstract}

Edgar Morin, "Beyond Determinism"

NABOKOV AND BORGES are often compared, but their responses to the field concept are very different: whereas Nabokov is drawn to it because its asymmetries promise to rescue art from being merely a game, Borges is attracted to it because its discontinuities reveal that everything, including itself, is no more than a game. The two stances are associated with very different literary strategies. As we saw in Chapter 5, the impetus of $A d a$ is to stop time; to create patterns whose parameters, once set, can encompass all future permutations; to make absolute and immortal the identity of the narrator, idiosyncrasies intact, by weaving his patterns of thought into the fabric of the created world.

Borges, by contrast, attempts to increase rather than use up the available permutations. Instead of hundreds of pages he writes five or six, characteristically including at least one open-ended catalogue capable of indefinite expansion. For Borges stasis is impossible because art is not an object to be framed, but a continuing process whose permutations are inexhaustible. In "Pierre Menard, Author of Don Quixote," for example, a changed context results in a completely different text. The Don Quixote of Pierre Menard, we are told, is a richer, subtler, and 
vastly different book from the Don Quixote of Cervantes, even though they use identical words. The assertion opens the way to an infinite number of Don Quixotes, all different once they are attributed to different writers and different historical contexts. ${ }^{1}$ In "Tlön, Uqbar, Orbis Tertius," we learn that in Tlön literary critics attribute wildly different words to the same imaginary author, and then they explore the psychology of "this interesting homme de lettres" ( $F$, p. 28). Different texts can thus give rise to a new author, just as imagining different authors can engender multiple texts from the same words. This view of art suggests that infinite sequence would be a natural-perhaps inevitable-metaphor for Borges to adopt. ${ }^{2}$ What stasis is to Nabokov, sequence is to Borges.

Borges's strongest links to the field concept are through the infinite sets that Cantor introduced into mathematics in the latter nineteenth century. Before we turn to a fuller exploration of this connection, however, some history and definitions of the mathematical terms involved may be helpful. To understand Cantor set theory, it is necessary to understand the distinctions between sequences, series, and sets. (Although Borges uses these terms interchangeably, I will follow standard mathematical usage.) In mathematics, a sequence is a list of terms, for example, $\mathrm{I}, 2,3 \ldots$ A series is the sum of terms associated with a given sequence, for example, $\mathrm{I}+2+3 \ldots$ A set is a collection of terms that can be combined in different ways; for example, the set $[1,2,3]$ can be combined into six subsets: $\{\mathrm{I}\},\{2\},\{3\},\{\mathrm{I}, 2\},\{\mathrm{I}, 3\},\{2,3\}$. An infinite series is the partial sums associated with a sequence that has an infinite number of terms, for example the sums we would get if we continued to add together the sequence of whole numbers $\mathrm{I}, 2,3 \ldots$ to infinity. Infinite series can be divided into two groups: convergent series, in which the sums converge to a finite value, for example $.3+.03+.003$ $+.0003+.00003 \ldots$, which converges to $\mathrm{I} / 3$; and divergent series, in which the sum of the terms cannot be expressed except as a mathematical formalism, because the sums do not "settle down" to a definable limit as the series progresses. The tendency of a series to diverge is not

1Jorge Luis Borges, "Pierre Menard, Author of Don Quixote," in Ficciones, ed. Anthony Kerrigan (New York: Grove, 1962) (hereafter F), pp. 45-56.

2In El idioma de los argentinos (Buenos Aires: n.p., 1928), Borges argues that the richness of a language cannot be equated with the number of words it contains, since "el solo idioma infinito-el de las matemáticas-se basta con una docena de signos para no dejarse distanciar por número alguno" (p. 170). 
always intuitively obvious. For example, the seemingly innocent progression $I-I / 2-I / 3-I / 4 \ldots$ is a famous instance of a divergent series. If the signs are alternately positive and negative $(I-I / 2+I / 3-$ $\mathrm{I} / 4 \ldots$ ), however, the series converges. A convergent series thus consists of the partial sums of an infinite sequence that nevertheless add up to a finite number, while a divergent series adds up to no definable sum at all. ${ }^{3}$

One of the earliest challenges to a deterministic universe came from infinite series; Zeno's famous paradox of Achilles and the tortoise uses the infinite series $\mathrm{I}+\mathrm{I} / \mathrm{IO}+\mathrm{I} / \mathrm{I} 00+\mathrm{I} / \mathrm{IO0O} \ldots$ to achieve its effect. As mathematicians soon discovered, however, the threat posed to determinism by infinite series could be defused by outlawing from mathematics actually infinite (as opposed to potentially infinite) sets of numbers. Consider for example the sequence 1, 2, 3... As long as we consider the sequence to consist only of those numbers we have named so far, the infinite progression implied by the ellipsis is only potentially present, looming in the future but never actually reached. If, however, we consider the entire sequence as a pre-existing entity, the sequence is not the progression but the complete set of whole numbers, which are infinite in number. This set is then actually rather than potentially infinite, since there are an infinite number of terms present in it.

It had been traditional since Aristotle to consider actually infinite sets as illegitimate entities, and to think of "infinity" as a single, unimaginably large number. All that changed, however, with Georg Cantor. Cantor argued that actually infinite sets were legitimate mathematical entities; he also maintained that it was possible to determine the relative magnitude of infinite sets, and consequently to prove that some were larger than others. Since Cantor believed that infinite sets obeyed their own peculiar arithmetic, he referred to them not as infinities but as "transfinite numbers." Cantor chose the aleph to represent these transfinite numbers, designating his smallest transfinite number, the set of whole numbers, as $\kappa_{0}$; the next largest infinite set, the set of real numbers, as $\boldsymbol{\aleph}_{1}$; the next largest as $\boldsymbol{\aleph}_{2}$, and so forth. Cantor then proved theorems about the relationship between these transfinite numbers that became the basis for Cantor set theory. We shall return to Cantor set theory when we discuss Borges's appropriation of it in "The Aleph."

\footnotetext{
${ }^{3}$ Kennan T. Smith, in his Primer of Modern Analysis, clarifies the distinction between sequences and series on pp. 90-92.
} 
Cantor set theory played a crucial role in the developments leading to the discovery of Gödel's theorem, and hence to those aspects of the ficld concept that emphasize self-referentiality. Although it is not correct, strictly speaking, to talk about a "field" in connection with Cantor ("field" has a different meaning in mathematical theories of groups), Cantor's unique contribution was to consider all the elements of an infinite set to be present (as he said) "at once," and thus to posit the number system as a pre-existing, interrelated totality. In making this shift, Cantor introduced into mathematics ambiguities and indeterminacies that we have seen to be characteristic of the field concept. Cantor himself realized this; he discovered that his set theory led unavoidably to paradoxes of self-reference.

Early in his work Cantor had demonstrated that for any infinite set, there is another one that is larger. Consider for example the set $\{\mathrm{I}, 2,3\}$. This set has three elements, and as we have seen, we can form from it six different combinations of these elements, or six subsets. We can intuitively appreciate, then, that the number of all possible subsets of a set will be larger than the original set. Since any set can be broken into its subsets, there will thus always be a number larger than any of the transfinite numbers. The problem arose in 1895 when, as Morris Kline explains, "Cantor thought to consider the set of all sets." ${ }^{4}$ Since this set includes all possible sets, its number should be the largest that can exist. However, Cantor had shown that the set of all subsets of any given infinite set must be larger than the original set itself. Hence if the set of all sets is broken into its subsets, the number of these subsets must be larger than the original set, which implies that there must be a number larger than the largest number. The problem arises because the set of all sets contains itself as a member, and so refers self-referentially to itself. Cantor was never able satisfactorily to resolve the paradox posed by the set of all sets. He finally said merely that it was necessary to distinguish between consistent and inconsistent sets, and that self-referential sets were inconsistent. ${ }^{5}$

By asserting that actually infinite sets were legitimate mathematical entities and then discovering that they led to apparently irresolvable paradoxes, Cantor paved the way for other mathematicians to recognize related paradoxes that were not merely in set theory, but deeply embed-

${ }^{4}$ Morris Kline, Mathematics: The Loss of Certainty (New York: Oxford University Press, 1980), p. 203.

5Ibid., p. 202. 
ded in the foundations of mathematics. In an attempt to eliminate these paradoxes, Bertrand Russell suggested that statements referencing themselves should be outlawed from mathematics. Unfortunately, selfreferencing statements (or, in Russell's terminology, "impredicative definitions") had been used in classical mathematics in important definitions, and it was not clear how they could be banished without abandoning some very useful and widely held theorems. The controversy became part of what Kline calls the "loss of certainty" in mathematics, resulting in the realization that mathematics is not the absolute truth it was once supposed to be, but is riddled with unprovable assumptions and irresolvable paradoxes. The controversy over Cantor set theory led directly to the attempt to axiomatize number theory, and this, as we saw in Chapter 2, led in turn to Gödel's proof that complete axiomatization is impossible. Cantor was thus inadvertently a seminal figure in the chain of events culminating in the realization that the field concept implies inescapable limits on what can be proved by logical analysis.

Borges's discussion of Cantor set theory in The History of Eternity shows him to be well in command of these basic concepts. Borges's familiarity with the history and import of Cantor set theory is further indicated by his review of Kasner and Newman's popularized account in Mathematics and the Imagination, shortly after it appeared in 1940.6 As his review makes clear, Borges not only understood Cantor's essential methodology, but also appreciated that it led directly to the discovcry of paradoxes of self-referentiality. In his review Borges mentions volumes in his library that he has "made hazy with manuscript notes," and predicts that Mathematics and the Imagination will take its place among those well-read few. ${ }^{7}$ Borges then goes on to list the "spells of mathematics" which are for him the most powerful; Strange Loops are the essence of this list. "There are almost innumerable versions of this method [of constructing self-referential paradoxes] that don't vary except in the protagonists or the fable," Borges notes. He then proceeds to list some of his favorites, including Bertrand Russell's discussion of "the set of all sets that don't [sic] include themselves" (D, p. I66).

Borges's review suggests that he was drawn to Cantor's work because

6Edward Kasner and James Newman, Mathematics and the Imagination (New York: Simon \& Schuster, 1940).

Torge Luis Borges, Discusion (hereafter D), vol. 6 of Obras Completas (Buenos Aires: Emecé Editores, 1957), pp. I65-166. 
he saw in it possibilities for creating new kinds of Strange Loops. As we saw in Chapter 2, it is when everything is connected to everything else through the mediating field that self-reference becomes a problem. It surfaces in its strongest form in the logical paradoxes of Cantor set theory. Borges is the first writer in this study who consistently wants to exploit rather than suppress these inconsistencies, because he hopes to use them to reveal the essential fictionality of the model. His intent is thus subversive.

His strategy is seduction, for he progresses to this revelation by several seemingly innocuous steps. The first step in his strategy is to transform a continuity into a succession of points, and to suggest that these points form a sequence; there follows the insinuation that the sequence progresses beyond the expected terminus to stretch into infinity; then the sequence is folded back on itself, so that closure becomes impossible because of the endless, paradoxical circling of a selfreferential system. This complex strategy (which may not appear in its entirety in any given story) has the effect of dissolving the relation of the story to reality, so that the story becomes an autonomous object existing independently of any reality. The final step is to suggest that our world, like the fiction, is a self-contained entity whose connection with reality is problematic or nonexistent.

Borges's best-known stories, particularly those anthologized in Ficciones and The Aleph and Other Stories, show the strategy in prototypical form. Although these stories have often been written about, the role of infinite sequences in them has not been generally recognized. The omission is the more surprising because Borges's work is so repetitive: the same themes, ideas, and paradoxes keep recurring. ${ }^{8}$ Borges himself is perfectly aware of this sparseness. In "Profession of Literary Faith," he writes, "I have already overcome my poverty; I have recognized, among thousands, the nine or ten words that accord with my heart." "But one of those "nine or ten words" - the concept of series-has yet to be fully

\footnotetext{
8The repetitiveness of Borges's work has been noticed by many critics, among them James E. Irby in his discussion of the mirror, the labyrinth, and the book as central symbols in Borges, The Structure of the Stories of Jorge Luis Borges (Ann Arbor: University of Michigan Microfilms, 1962), pp. 270-285. How easily Borges's work may be classified in terms of its central metaphors may be seen in the way Ana María Barrenechea organizes her material in La expresión de la irrealidad en la obra de Jorge Luis Borges (Buenos Aires: Ed. Paidos, 1967), trans. as Borges the Labyrinth Maker, trans. Robert Lima (New York: New York University Press, 1965).

9From El tamaño de mi esperanza, quoted in Ronald Christ, The Narrow Act: Borges' Art of Illusion (New York: New York University Press, 1969), p. II.
} 
recognized. ${ }^{10} \mathrm{We}$ will therefore consider a few of these stories to see how the general strategy works, before turning to its more specific application in "The Aleph."

The well-known "Tlön, Uqbar, Orbis Tertius" provides an example of the first steps in Borges's subversive strategy. The story opens in the familiar setting of casual after-dinner conversation, with Bioy Casares recalling that "one of the heresiarchs of Uqbar had stated that mirrors and copulation are abominable, since they both multiply the numbers of men" $(F$, p. 23). Soon this predicted series of specular worlds begins to appear in earnest. The source of the aphorism, we learn, is an clusive article in The Anglo-American Cyclopedia on the apparently nonexistent country of Uqbar. In the article, reference is made to Tlön, an imaginary region that is the subject of Uqbar's literature. Tlön, a fantastic region written about in a country which already cannot be located on any map, thus exists at several removes from reality, having its being for the moment only as a passing reference in a single variant copy of a pirated encyclopedia. With the discovery a few years later of the eleventh volume of $A$ First Encyclopedia of Tlön, however, Tlön begins to emerge from textuality into actuality. In the end, Borges tells us, the world becomes Tlön. As we witness this transformation, we can sec Borges's strategy evolving from the first tenuous suggestion of a sequence to the infinite progression of a self-referential Strange Loop.

Series, particularly nuances in number systems, are crucial to this transformation. A footnote intimates that in Tlön, base twelve rather than base ten is used for counting. ${ }^{11}$ Gradually, we are led to suspect that base twelve is also the operative counting system within the story, which implies that as the world becomes Tlön, the text is also becoming a Tlönist document. Borges achieves this modulation by a subtle emphasis on the number eleven-a number that encourages us to proceed beyond the expected terminus of the decimal system. The volume of Tlön's First Encyclopedia that Borges first uncovers is the eleventh; heresies of the eleventh century are documented; brönir of the eleventh

\footnotetext{
${ }^{10}$ Barrenechea, for example, despite her thorough and perceptive analysis of Borges's major motifs, does not even list "series" in the index.

${ }^{11 T h e ~ f o o t n o t e ~ g l o s s e s ~ t h e ~ p h r a s e ~ " e l e v e n t h ~ c e n t u r y ~ h e r e s i a r c h ~ o f ~ T l o ̈ n " ~ b y ~ e x p l a i n i n g ~}$ that in the duodecimal system, a century is composed of one hundred and forty-four years. The number is the square of twelve or twelve twelves, analogous to the hundred years or ten tens that comprise a century in the decimal system. The footnote thus indirectly establishes that in Tlön, the duodecimal rather than the decimal system is used for counting.
} 
degree are emphasized as having "a purity of form which the originals do not possess" ( $F$, p. 30).

The transition number, eleven, has a dual function. It leads us beyond the decimal system, yet falls short of the expected terminus of the duodecimal system. The withholding of the final term is important, for repeatedly a terminus is suggested, only to be transformed into an indefinitely continuing sequence. The eleventh volume of the First Encyclopedia, for example, though at first it is the only volume in existence, refers to "both subsequent and preceding volumes"; its "apparent contradictions" ( $F$, p. 22) provide the basis for proving that other volumes exist, volumes which will in turn be superseded by the yet more numerous volumes of the succeeding edition. Hrönir of the eleventh degree are purer than the originals, suggesting a point of termination; but brönir of the twelfth degree "deteriorate in quality," so the process "is a recurrent one" (F, p. 30). Even within the duodecimal system, the final term never quite arrives.

As single terms stretch into sequences, and as sequences modulate into nonterminating progressions, the locus of reality becomes correspondingly indeterminate. In the idealist metaphysics of Tlön, there is no reality independent of one's thoughts of reality; it is sufficient to search for a thing to bring it into existence. In Tlön the $u r$ is a "thing produced by suggestion, an object brought into being by hope" ( $F$, p. 30). There is the suggestion that Tlön itself is an $u r$-object, a reality brought into being by believing it exists. As scholars, alerted to the mystery of Tlön, begin searching for evidence of its existence, more and more evidence in fact appears, from the missing volumes of $A$ First Encyclopedia to Tlönist artifacts. The implied progression suggests that the Terran scholars created Tlön by searching for it.

Meanwhile, the theorists of Tlön are reconstructing (or constructing?) our world through the parable of the nine coins, in which they try to imagine the continuous existence of matter through time. As eleven is the penultimate term of the duodecimal system, nine is the penultimate term of the decimal system. Our world conceives of Tlön in the eleventh volume; Tlön conceives of us in nine coins. Through the conjunction of the penultimate terms of the two number systems, each world seems to be evoking the other as the final, inevitable, and yet almost unimaginable last term of the alien number system it entertains.

But this terminus, like others in the story, is illusory. If our world can become Tlön, and Tlön can become our world, the exchange can take 
place again-and again. At some future date, when we have become Tlön, our philosophers will propose the paradox of the nine coins. Meanwhile, in the world that was once Tlön and is now a materialist society, a variant text appears alluding to a mysterious region where any other philosophy except idealism is inconceivable. The sequence thus posited implies that the two worlds will become each other in turn, each calling the opposite world into being through the penultimate terms of a sequence that never ends. Text metamorphoses into context, context into text, text into context, in a Strange Loop that makes the distinction between "fiction" and "reality" an undecidable question.

An even more bizarre sequence, based on another progression implicit in the text, is possible. On an occasion when the narrator is conversing with Herbert Ashe, whom we later learn is one of the "demiurges" responsible for creating Tlön, the discussion turns to the "duodecimal number system." Why Ashe, one of the creators of the duodecimal-based Tlön, should want to construct tables converting decimals to duodecimals is quite clear in retrospect to us and to the narrator, who laments that "nothing more was said-God forgive me-of duodecimal functions" ( $F$, p. 2I).

Ashe's conversion tables, however, do not end there. The narrator recalls Ashe's comment that "as a matter of fact, he was transcribing some duodecimal tables . . . into sexagesimals (in which sixty is written IO), adding that this work has been commissioned...” $(F$, p. 2I). Apparently the plan of the secret society to which Ashe belongs is that the incredible world of Tlön, based on a duodecimal system, is to be succeeded by the unimaginable world of Orbis Tertius, based on the sexagesimal number system. Tlön was brought into being through the discovery of $A$ First Encyclopedia of Tlön; the adjective "first" implies a sequence, a second term. Are the forty volumes of the first edition to be followed, as the narrator suspects, by the hundred volumes of $A$ Second Encyclopedia, "another work, more detailed, and this time written, not in English, but in some one of the languages of Tlön" ( $F$, p. 32), which in turn will call the third world of Orbis Tertius into being? The progression implies a sequence of worlds, each calling its successor into being in an increasingly unimaginable sequence that has no end. Infinite sequences, by combining known terms with an unattainable end point, exhibit the paradoxical qualitics of boundedness and infinite regress. In Borges's story, as each term comes into vicw, another term 
looms behind it, so that regardless of how many terms are accepted, with whatever resignation, statis is never achieved.

The sequences in this story, however, do not only contain inherent paradoxes; they also harbor an inescapable contradiction. ${ }^{12}$ The contradiction arises in the following way. We are given to understand that Tlön is a world of “extreme idealism.” In Tlön's idealist metaphysics, each state of being is conceived of as separate and unconnected with preceding and succeeding states. Tlönist philosophy would thus deny the possibility of a sequence, since the terms of a sequence by definition form a connected progression. So in creating Tlön as one of the worlds that exist in a connected sequence, Borges has posited a sequence which contains within it a term, Tlön, that denies the possiblity of sequence. The internal contradiction destroys whatever feeling of certainty we may derive from inferring that the sequence will proceed in a stable progression. Stasis-even the stasis of constant metamorphosis through the terms of a sequence-is undercut to leave us in a fluid state where nothing is certain. "Now, in all memories," Borges writes, "a fictitious past occupies the place of any other. We know nothing about it with any certainty, not even that it is false" $(F$, p. 34).

Jaime Alazraki has suggested that the obvious parody behind the forty volumes of A First Encyclopedia of Tlön is the Encyclopedia Britannica. He infers from this that Tlön, created by a secret society of geographers, chemists, artists, and algebraists, is a thinly veiled metaphor for our own world, which is also a social construct created by a society of chemists, geographers, artists, and algebraists, and described in an encyclopedia. ${ }^{13}$ Might we infer, then, that Borges is re-creating in this story an elusiveness that he sees as characteristic of reality? This hypothesis implies that we have some notion of what reality is - that is, that it has the quality of regressing before us. But even this modest hypothesis Borges sabotages in the following often-cited passage.

\footnotetext{
${ }^{12}$ Frances Wyers Weber, in "Borges' Stories: Fiction and Philosophy," Hispanic Review, 36 (1968), I24-I4I, makes the point generally about Borges's fictions that they are "self-reversing tales." What happens with series is a special example of this general paradigm.

13Jaime Alazraki, "Tlön y Asterión: Metáforas Epistemológicas," in Jorge Luis Borges, ed. Jaime Alazraki, No. 88 in El Escritor y la Critica (Madrid: Taurus Ediciones, S.A., 1976), pp. 192ff.
} 


\section{Literary STRATEgIES}

Almost immediately, reality gave ground on more than one point. The truth is that it hankered to give ground. Ten years ago, any symmetrical system whatsoever which gave the appearance of order-dialectical materialism, anti-Semitism, Nazism-was enough to fascinate men. Why not fall under the spell of Tlön and submit to the minute and vast evidence of an ordered planet? Useless to reply that reality, too, is ordered. It may be so, but in accordance with divine laws-I translate: inhuman lawswhich we will never completely perceive. Tlön may be a labyrinth, but it is a labyrinth plotted by men, a labyrinth destined to be deciphered by men. (F, p. 34).

According to the narrator, we can know nothing about reality. All we can be sure of is that if we may decipher its principles, then it is not reality but a labyrinth, that is to say, an artifact. Even the assumption that the artifact reproduces the order characteristic of our experience of reality is tenuous, since according to the idealist philosophy of Tlön that experience itself is a creation of our own minds. It is therefore not possible to assume that the fiction is verisimilar.

It is also, oddly enough, not altogether possible to assume that it is not verisimilar. This further complication arises from the internal contradictions within the story. That the fictional world is inconsistent means that we cannot be sure if even the artifact is ordered, which in a curious way makes it again verisimilar to reality. If it is impossible to arrive at the final truth within the fiction, it may be like reality after all, its very inaccessibility rendering it mimetic. The reasoning is, of course, circular.

This leads us to the next step in Borges's strategy: after he insinuates a sequence, he subverts it by making it a circle or by making the sequence consist of a single term that repeats itself endlessly. In this turning of a sequence back on itself, Strange Loops can appear that render reality itself an undecidable proposition. The elaborate, circuitous turnings in "The Approach to al-Mu'tasim" illustrate the technique.

The form of this story is a review of a labyrinthine novel about the fabled al-Mu'tasim. At first the reviewer assumes that the solution to the labyrinth can be found when the protagonist finds the man for whom he searches. Almost unnoticed is an antecedent to this proposition: that in suggesting the search takes place through progressive revelations, the reviewer has transformed the narrative continuity of the 
novel into a sequence. The strategy becomes explicit when he suggests, "A mathematical analogy may be helpful here. Bahadur's populous novel is an ascendant progression whose last term is the foreshadowed "man called al-Mu'tasim." 14 When the novel's hero draws the curtain from al-Mu'tasim at the novel's end, it seems that the terminus has been achieved.

That termination is soon undercut, however, by the reviewer's revelation of a 1934 version of the novel which "declines into allegory," an allegory in which al-Mu'tasim is a God who "is also in search of Someone, and that Someone of Someone above him . . . and so on to the End (or rather, Endlessness) of Time, or perhaps cyclically" ( $A$, p. 50). As the apparent Source recedes into an unattainable end point, undercurrents of circularity further complicate the idea of the pilgrimage as a linear progression to a finite terminus. The hero's journey traces a circle, beginning in Bombay and ending there. It begins with a riot between the Muslims and the Hindus, "God the Indivisible against the many Gods" ( $A$, p. 46). But this difference collapses into identity when we learn that different men see God differently, according to the biases of their religions; therefore the One is also the Many, appearing to the "many varieties of mankind" in the multiform guises demanded by their differing expectations. Because the One and the Many are indistinguishable, the religious dispute responsible for beginning the pilgrimage is based on an illusion; but this realization comes about only by virtue of the pilgrimage. The reviewer drily comments that "the idea is not greatly exciting" ( $A$, p. 50), without noting that it makes of the pilgrimage an intellectual as well as a physical circle.

Another idea excites the reviewer more. In the twentieth chapter, certain phrases attributed to al-Mu'tasim appear to be "the mere heightening of others spoken by the hero; this and other hidden analogies may stand for the identity of the Seeker with the Sought" ( $A$, p. 50). Again difference collapses into identity as the reviewer remarks, with some exasperation, that the novel's supposed author, Mir Bahdur Ali, "cannot refrain from the grossest temptation of art-that of being a genius" ( $A$, p. sI).

What the reviewer chooses not to recognize is related circularities in

${ }^{14}$ Jorge Luis Borges, "The Approach to Al-Mu'tasim," The Aleph and Other Stories, 1933-1969, ed. and trans. Norman Thomas di Giovanni in collaboration with Borges (New York: E. P. Dutton, 1970) (hereafter $A$ ), p. 49. 
his own essay, beginning with the fact that he is creating the novel by describing it. But the illusion of difference is important, for it allows the reviewer also to be a seeker, searching for the novel's meaning. His search at first seems to be moving away from the novel in a linear progression. He begins with a plot summary of the novel; then he gives various interpretations of the difference between its two versions; finally he adds a concluding section in which he adduces various literary analogues, from Kipling to The Faerie Queene, putting forth "the Jerusalem Kabbalist Isaac Luria" as his own choice for the novel's source. The narrator's attempt to move closer to the original 1932 version by first examining the 1934 version (the only one he has seen) and then adducing increasingly remote literary predecessors seems perversely to be carrying him in the wrong direction. But in the most remote section of all, a footnote on a possible literary analogue in the parable of the Simurgh, the narrator's pilgrimage is also revealed as a circle. For the footnotes confirms that the parable of the Simurgh is really another version of the novel. The thirty birds seeking the Simurgh realize that, by virtue of their arduous journey and consequent purification, they have become the Simurgh. The Seeker is again revealed as identical with the Sought, the journey with its end. The footnote ends with Plotinus's "divine extension" of the principle of identity: "All things in the intelligible heavens are in all places. Any one thing is all other things. The sun is all the stars, and each star is all the other stars and the sun' " $(A, \mathrm{p}$. 52). The identity of the footnote, an appendage to the addendum to the review of the text, with the text's central meaning is another way of converting the linear into the circular, and of confirming the principle of identity laid down by Plotinus.

The narrator as seeker after the novel is identical with that which he seeks in another sense, for the novel does not exist outside his essay. His exasperated admiration for the novel's complexities, his stance as a critic examining the novel objectively, create an illusion of difference that collapses in the final realization of identity as the circular, circuitous journey of the essay brings him back, through the footnote, to the core of the novel, which is also his review. The transformation of apparent linearities into circularities implies that the sequence closes back on itself, so that differences collapse into similarities and eventually into identity. This is, of course, precisely the kind of circling back that is characteristic of self-referential systems. The sense of moving along, of 
coming closer to an end point, is revealed not exactly as an illusion but as a half-truth as the seeker merges with the sought, the periphery with the center, the journey with its end. The effect is to create a selfreferential field from elements that we initially take to be separate and distinct.

Where Borges's fiction differs from scientific models of the field concept, however, is in using the concept to suggest that everything, including reality, is a fiction. Scientific models, by contrast, are useful only because they are presumed in some way to reflect reality. The difference leads to very different views of Strange Loops in science and in Borges. For Cantor, for example, Strange Loops were an embarrassment, but for Borges they are an embarrassment of riches because they allow him to draw into question the assumption that there is a "reality" to reflect. This predilection of Borges's is clear in "The Library of Babel," a fable in which the library and the world become synonymous. In this story designed to draw our attention to the artificiality of both the word and the world, we see the final step in Borges's seductive strategy, the inclusion of the reader himself in the circle of the fiction's Strange Loop. The narrator of this story, who refers to himself as a Librarian, is convinced that the intensely symmetrical order of the Library has to conceal meaning somewhere among its symmetries. But he (and we) slowly realize that order is not the same as meaning. The dilemma is extended to cosmic proportions when the narrator comes to what he calls the "capital fact" of his history. Clearly the Library must be infinite, the narrator argues; but the number of books derivable from all possible combinations of letters, though very large, is still finite. The narrator suggests that the answer to the dilemma lies in realizing that finite terms can become an infinite series if they are continued indefinitely. After exhausting the permutations provided by the twenty-five orthographic symbols the Library simply repeats itself, thereby becoming "limitless and periodic." The narrator speculates that the larger sequence of repeated terms would then possess an order, the order of repetition. "If an eternal voyager were to traverse [the Library] in any direction," the narrator concludes, "he would find, after many centuries, that the same volumes are repeated in the same disorder (which, repeated, would constitute an order: Order itself)" (F, pp. 87-88). "My solitude rejoices in this elegant hope," he ends.

But the narrator's "solution" is of course an answer only in a very 
narrow sense. While it suggests a way to transform randomness into ordered sequence, it contains no hint of how that sequence may be rendered intelligible or meaningful. Even if order is assured, sense is not; the problem of what the Library or its books mean remains unanswered. The narrator's solution is significant not because it is satisfying, but because it is inevitable. It reveals how desperate is the human need to find meaning somewhere, even if only in the repeated order of meaningless sequence. "Let me be outraged and annihilated," the narrator prays, "but may Thy enormous Library be justified, for one instant, in one being" ( $F$, p. 86).

Almost as inevitable is the appearance of a Strange Loop; this time it extends to encompass the reader. The narrative we read is contained in a book, the book we hold in our hands. But if, as the narrator claims, the Library contains all possible books, an identical text is also somewhere among the Library's volumes. Which then are we reading, the narrator's history or the Library's book? The narrator specifically contrasts his "fallible hand" scribbling his story on the end leaves of a book with "the organic letters inside: exact, delicate, intensely black, inimitably symmetric" ( $F$, p. 8I). Logic demands that we conclude the present text in hand (which of course is printed) to be the Library's book. What we have is not the narrator's handwritten text but a mirror of it, or perhaps one of the "several hundreds of thousands of imperfect facsimiles" $(F$, p. 85$)$.

That the account is inaccurate in indeterminable ways is one implication; even more important is the implication that we are reading the Library's book. This in turn implies that we, like the narrator, are within the Library examining one of its volumes, which means that we, no less than the narrator, are contained within one of the books we peruse. The narrator's remark that "the certainty that everything has been already written nullifies or makes phantoms of us all" ( $F$, p. 87) takes on a disturbing new meaning as we realize that we too must be within one of the Library's books. "Why does it disquiet us to know that Don Quixote is a reader of the Quixote, and Hamlet is a spectator of Hamlet?" Borges asks in "Partial Enchantments of the Quixote." "I believe I have found the answer: those inversions suggest that if the characters in a story can be readers or spectators, then we, their readers and spectators, can be fictitious." 15 With this realization comes the

15Jorge Luis Borges, "Partial Enchantments of the Quixote," in Other Inquisitions, 1937- 
corollary awareness that the Strange Loop now encompasses us within its circumference.

Sequences thus play an important role in allowing Borges to develop the idea that both his fictions and the world are self-referential systems. They are no less important in providing him with a model for the structure of his stories. The possibilities are implicit in Zeno's Second Paradox, the parable of the tortoise who has a head start and goes one length before the hare begins. But after the hare has gone one length, the tortoise has gone one and one-tenth lengths, so the tortoise is still ahead. The paradox lies in the fact that no matter how far the hare goes, the tortoise is always one-tenth the distance ahead. The argument owes its force, Borges points out in "Avatars of the Tortoise," to the series I $+\mathrm{I} / \mathrm{IO}+\mathrm{I} / \mathrm{IOO}+\mathrm{I} / \mathrm{I}, 000+\mathrm{I} / \mathrm{IO}, 000 \ldots$ (OI, p. IIO). The method suggests that infinity can be made to stretch between any two points simply by converting distance from a continuum to an infinite series of decreasing magnitude.

We have seen how Borges uses this idea in developing the plots of his stories; he also uses it in constructing the paradoxes that reveal the fictionality of the model. Continuity, particularly continuity of space and time, implies that moving from point $A$ to point $B$ requires traversing the intermediate distance. Borges prefers, on the contrary, to break continuities into sequences so that point A suddenly turns into point $B$ (or point $\mathrm{Z}$ ). Because the transition between terms is discontinuous, it is also possible for Borges to suggest that space intervenes between terms-and into this space he can insert a sub-series of infinite length. He thus gains two advantages from sequences that he could not derive from continuities: the ability to effect abrupt transitions between discontinuous terms (for example, by positing opposites as terms of the same sequence so that progression along the sequence suddenly transforms one thing into its opposite); and the ability to suggest that infinity can stretch between any two terms of the sequence, thus rendering any real progression an impossibility.

In addition to its thematic uses, the inherent discontinuity of a sequence provides a model for the narrative structure of the stories. The "middle distance" that narrative fiction usually extends is excised in Borges through ellipses and sudden breaks that transform a chronologically continuous story into a series of disconnected narrative points.

I952, trans. Ruth L. C. Sims (Austin and London: University of Texas Press, 1964) (hereafter $O I$ ), p. 46. 
With the collapse of the "middle distance," the length we traverse is defined less by the duration of the narrative than by the implied distance contained between the ellipses (which can be infinite). It is as if the linear spatiality of narrative fiction has been transformed into the repeated downward plunges one might endure in attempting literally to traverse a sequence. In this metaphorical, Borgesian view of sequence, the spaces between terms are as important as the terms themselves. The discontinuities facilitate the abrupt leap of thought necessary for the essential paradoxes to emerge. They also create gaps that make it impossible even to estimate where the bottom might be. The sequence, implicit chasms yawning between its apparently adjacent terms, thus plays a metaphoric as well as conceptual role in the fictions, serving as both sign and symbol in Borges's fictional mode.

So far I have been speaking of a sequence as an infinite progression of discontinuous terms. We are ready now, however, to consider the Cantorian view of an infinite series as a single entity, a pre-existing whole defined by the entire sum of terms. As we have seen, this view of series allows infinity to be encapsulated, as it were, within the bounds defined by the initial and final terms. Borges, aware of Cantor's work, sees in transfinite set theory new possibilities for representing infinity within the finite bounds of his short stories - and also new threats to the "wildness" that he loves in infinity. Never merely a reporter of ideas, Borges subjects Cantor's theory to what Harold Bloom would call a "strong reading," deforming it in ways that reveal what he hopes to gain by infiltrating his fictions with infinite serics and sequences.

Cantor was able to answer the question "How large is infinity?" by placing infinite sets in one-to-one correspondence. "The operation of counting is nothing more for [Cantor] than that of comparing two series," Borges comments in his discussion of Cantor set theory in "The Doctrine of Cycles." 16 The idea is to match up each element of set A with an element from set $\mathrm{B}$; if it can be shown that the matching is complete, with no elements left over in either set, then the two sets can be said to be equal in size, even though the number of elements in each is infinite and therefore not countable. As Borges points out, we can show that the number of odd numbers is equal to the number of even numbers by using this one-to-one correspondence method (BR, p. 67):

${ }^{16}$ Jorge Luis Borges, "The Doctrine of Cycles," in Borges: A Reader, ed. Emir Monegal and Alistair Reid (New York: E. P. Dutton, 198I) (hereafter BR), pp. 66-67. 
I corresponds to 2

3 corresponds to 4

5 corresponds to 6 , etc.

Though Borges does not say so, it is also possible to show that the number of odd numbers alone is equal to the total number of both odd and even numbers by a similar procedure:

I corresponds to I

3 corresponds to 2

5 corresponds to 3

7 corresponds to 4 , etc.

Using this method, Cantor arrived at the paradoxical result that a subset (or partial grouping) of an infinite set is as large as the complete set itself. In fact, Cantor defined an infinite set as a set that can be put into one-to-one correspondence with one of its proper subsets. Borges makes the correct, but to a non-mathematician surprising, observation that "there are as many multiples of 3018 as there are numbers [that exist]—without excluding from these 3018 and its multiples" (BR, p. 67). The proof follows the earlier method:

I corresponds to 3,018

2 corresponds to 6,036

3 corresponds to 9,054

4 corresponds to 12,072 , etc.

What fascinates Borges about these results from Cantor set theory is the idea that "in these elevated latitudes of enumeration, the part is no less copious than the whole: the exact quantity of points there are in the universe is the same as in a meter, or in a decimeter, or in the farthest stellar trajectory" (BR, p. 67). Borges sees in Cantor's proposition a way to escape the bounds of finitude, for if any part, however minute, of an infinite set can also contain infinity, infinities can be opened within any element, no matter how small, simply by suggesting that it is part of an infinite series. "If the universe consists of an infinite number of terms," Borges writes, "then it is absolutely capable of an infinite number of combinations, and the need for a recurrence is invalidated" (BR, p. 67).

In its immediate context, this result enables Borges to refute Nietzsche's doctrine of Eternal Return. In the larger context of Borges's stories, Cantor's results seem to promise that a fiction composed of a limited number of words can, like the subsets of an infinite set, nevertheless contain infinity. In "The Aleph," Borges appropriates Cantor's 
nomenclature and methodology to explore the implications for literature that obtain when infinity is encapsulated within a finite boundary.

The bounded but infinite topography of the Aleph, a sphere a little over an inch in diameter that contains "all space ... actual and undiminished" ( $A$, p. 26), contrasts with the bounded and finite topography of the Garay Street house. The narrator's fixation on Beatriz Viterbo suggests that the arrangement of the locale is a parodic mirroring of Dante's Divine Comedy, containing, like that larger topographical work, a three-tiered structure-defined, in "The Aleph," by the cellar, the drawing room, and the modern salon-bar next door. ${ }^{17}$ Borges subjects the work of his Italian predecessor to a number of playful inversions: the narrator experiences his epiphany in the lowest, rather than the highest, realm; the Aleph resides in the cellar, while the salon-bar is a horror of modern decor. But these inversions only help to highlight the assumptions that the narrator and Dante share. In using topographical symbolism, both Dante and the narrator assume that space can be assigned symbolic significance, and that this significance can be compressed into, and expressed through, an object in the center of that space. In one sense,the object at the center of that space is Beatrice/Beatriz; in another sense, it is the poem/fiction itself. The parody thus acts to link the narrator's literary strategies with the large body of traditional literature that, like the Divine Comedy, aspires to express the ceaseless flux of the infinite universe through a symbolic structure that is itself bounded and finite.

The existence of the Aleph, however, forces the narrator (and us) to question these assumptions. Daneri reverses Borges's procedures. Daneri has no need to resort to symbols to express the essence of the whole, because he is the possessor of an object that literally contains it. He attempts to create a literary counterpart to the Aleph in his poem entitled, appropriately, "The Earth," in which he intends to "set to verse the entire face of the planet" ( $A$, p. 19). With the Aleph rather than Virgil as his guide, he believes that literature operates like transfinite mathematics, which implies that the part is as large as, and therefore can contain, the infinite whole. Borges warns that the use of the word "Aleph" for the "strange sphere in my story may not be acciden-

\footnotetext{
${ }^{17}$ The Dante parody is discussed at length in Alberto J. Carlos's "Dante y 'El Aleph' de Borges," Duquesne Hispanic Review, s (1966), 35-50; see also Stelio Cro, "Borges e Dante," Lettere Italiane, 20 (1968), esp. 407-4IO.
} 
tal"; 18 "for Cantor's Mengenlehre, it is the symbol of transfinite numbers, of which any part is as great as the whole."19 As Borges recognizes, Cantor's work can, if applied to literature, have serious implications for literary methodology. Daneri's procedure illustrates them.

For Daneri, poetic creation consists of putting a subset of reality, the series of signs that comprise language, into one-to-one correspondence with the larger, infinite set of the world. He bases his method on the hint provided by the Aleph. The "formal perfection and scientific rigor" ( $A$, p. 2I) that Daneri claims for his poem is perfectly correct, if we assume that the world is an infinite set and language one of its subsets, for as we saw, Cantor proved that a subset of an infinite set is as large as the set itself. It is therefore theoretically possible to put the verbal signs into one-to-one correspondence with the infinite sets of the elements that comprise the world. This possibility drastically alters the role that artistic choice plays in literary composition, for when literature is a series of signs to be put into one-to-one correspondence with the world, choice is reduced to deciding which sign to match with which object. Daneri's fickleness in searching for the right sign only emphasizes how unimportant choice has become.

The narrator's fixation on Beatriz, by contrast, renders choice absolute. Rather than being reduced to a minimum as it is in Daneri's poem, choice for the narrator is the mysterious mechanism whereby the infinite multitude of other terms in the world can be made less significant than the privileged one upon which his choice operates. We learn in the course of the story that Beatriz was frail and stooped; that she wrote incestuous, pornographic letters to her cousin; that she was forgetful, distracted, and contemptuous, with a "streak of cruelty" that perhaps "called for a pathological explanation." But these imperfections in no way undermine the power of the artistic choice that identifies her as an ideal love-object. On the contrary, by testifying to the inexplicability of this choice, Beatriz's imperfections emphasize its absoluteness.

\footnotetext{
18The other significance Borges claims for the Aleph is that "for the Kabbala, that le tter stands for the En Soph, the pure and boundless godhead" (p. 29). This aspect is discussed in Salomon Levy's instructive article, "El Aleph, símbolo cabalístico, y sus implicaciones en la obra de Jorge Luis Borges," Hispanic Review, 44 (1976), I43-16I.

${ }^{19}$ Quoted from p. 29, The Aleph and Other Stories. The full title for Cantor's article is "Beiträge zur Begründung der transfiniten Mengenlehre." Part I appeared in Mathematische Annalen, 46 (1895), 48I-512, and part 2 in the same journal, 49 (I897), 207-243. An English translation can be found in Contributions to the Founding of the Theory of Transinite Numbers, trans. P. E. B. Jourdain (Chicago: Open Court, 1915).
} 


\section{Literary STRATEgIES}

This emphasis on choice is significant, for central to the debate that arose over Cantor's transfinite numbers was his method of arbitrarily selecting one element from each of several sets and using them to form a new set. This procedure became known as the "Axiom of Choice," and has since become one of the most controversial axioms of modern mathematics. The importance of the Axiom of Choice to Cantor set theory may be one reason why Borges makes the role of choice in literature an issue in the conflict between the narrator and Daneri.

It is an interesting footnote to Borges's story that in the early I90os the Axiom of Choice was used to develop the Banach-Tarski paradox, which states that given any two solid spheres (one, for example, the size of a golf ball and the other the size of the earth), each can be divided, as Morris Kline explains, into a "finite number of non-overlapping little solid pieces, so that each part of one is congruent to one and only one part of the other." 20 This implies, as Kline points out, that "one can divide the entire earth up into little pieces and merely by rearranging them make up a sphere the size of the ball." 21 I hasten to remind the reader that this is not Borges's fancy, but a logical consequence of the Axiom of Choice as it is used in modern set theory.

Given these results, it is not surprising that the Axiom of Choice is as central to Borges's story as it is to Cantor's theory. We have seen that for Daneri, choice is simply a matter of matching words to objects in one-to-one correspondence; in this he follows Cantor's own methodology. For the narrator, by contrast, choice is the mechanism whereby the world as a series is first negated by denying its plenitude, then reconstituted (in a form congenial to his temperament) from the single element favored by his choice. Far from using choice to validate series, then, the narrator uses it to deny series. The narrator's antipathy to series is as clear as Daneri's infatuation with them. Whereas Daneri delights in timetables, bulletins, and other paraphernalia that emphasize the seriality of time, the narrator is "pained" by the realization of a "wide and ceaseless universe" in which every small change is "the first of an endless series" ( $A$, p. I5).

These different views invite the question, which is closer to Borges's

${ }^{20} \mathrm{Kline}$, pp. $269-270$. For the example of the golf ball we could, of course, substitute Borges's Aleph, a sphere "an inch in diameter."

${ }^{21}$ Ibid., p. 270. 
own preferences? Borges's strategy follows neither Daneri's one-to-one correspondence method nor the narrator's symbolizing, though it draws on both. Daneri admits the plenitude of the world but does not see that choice is inevitable; the narrator admits choice, but denies the inevitability of the "endless series." Borges can have the best of both methods because he is willing to give up the one assumption that Daneri and the narrator share: that the world exists, and can be represented in literature. Illusion and symbol are therefore admissible, since he has surrendered Daneri's claim to rigorous correspondence; and infinitude is also possible, since he is not bound to the narrator's desire for a single, determinate locus for reality. The Aleph for Borges is not reality but a symbol of the kind of paradox that reveals the impossibility of ever representing reality.

In this distinction lies a crucial difference between Borges and Cantor. Even though Cantor was never able to demonstrate that the paradoxes inherent in his set theory could be resolved, he deeply believed that they were resolvable. As the attacks on transfinite number theory grew, Cantor retreated to Platonism for his defense. To Cantor, the alephs were valid mathematical entities because they were ideal objects in the Platonic realm of ideas. Cantor's scientific biographer Joseph Warren Dauben describes how, in Cantor's famous "Mengenlehre" paper, Cantor argued that the paradoxes of his set theory were resolvable because they corresponded to a Platonic reality that was itself consistent. ${ }^{22}$ In the ultimate, Platonic sense, Cantor believed that his theory was true because the Alephs were real.

Borges, of course, believes no such thing. In his History of Eternity,

22Joseph Warren Dauben, Georg Cantor: His Mathematics and Philosophy of the Infinite (Cambridge: Harvard University Press, 1979). Dauben calls the sentence with which Cantor begins the "Mengenlehre" treatise a "classic," and adds that it set "the tone for all that was to follow": "Definition: By a 'set' we mean any collection $M$ into a whole of definite, distinct objects $m$ (which are called the 'elements' of $M$ ) of our perception [Anschauning] or of our thought" (Dauben, p. 170). By defining a set as a collection of elements of our thought, Cantor was able to avoid the distinction that his critics sought to make between the merely abstract existence that transfinite numbers had and the referential existence that various elements within the set may possess. "This characteristic [of the elements in the set as objects of thought] was tremendously important to Cantor in an ontological way," Dauben comments. "If all the elements of his set theory existed on the same level, with the same reality of thoughts and images of the mind, then there was no dependence upon real objects of any sort. . . . The reality of sets as abstract objects in the mind then carried over directly to the transfinite numbers, and conferred upon them a similar sort of reality" (Dauben, p. 171). 
Borges impishly suggests that the Platonic realm of eternal archetypes is a huge museum of dusty pieces that serves mostly to frustrate the cabinetmakers of the world as they pursue the unreachable Platonic table. ${ }^{23}$ Because Borges does not accept the Platonic reality as "real,"24 he is also not obliged to accept Cantor's belief that the paradoxes of selfreferential systems can be resolved. The Alephs interest Borges not because they are real, but because they allow him to suggest that nothing is "real." This difference in strategies suggests parallel differences in motivation. Whereas Cantor wanted to extend logical analysis, not destroy or compromise it, Borges wants to use logical analysis to show how profoundly illogical its results can be.

The Aleph thus finally means something very different for Borges from what it means for Georg Cantor. ${ }^{25}$ Cantor chose the aleph to represent his transfinite numbers because it is the first letter of the Hebrew alphabet, and he hoped that his alephs would be a new beginning for mathematics. ${ }^{26}$ In Borges's story, the Alcph also represents fresh beginnings. But Borges is aware that it is a beginning that threatens to burst out of, rather than extend, logical analysis. When the narrator's egoistic eye ("I") attempts to establish bounds around the Aleph by looking at it from "cvery point and angle," he sees in it "the earth and in the earth the Aleph and in the Aleph the earth . .." $(A, \mathrm{p}$. 28), in a progression that circles back on itself to form a Strange Loop that includes the narrator within its circumference. According to the

23Jorge Luis Borges, Historia de la Eternidad, vol. I of Obras Completas (Buenos Aires: Emecé Editores, 1953), p. 21 .

${ }^{24}$ In an interview with Ronald Christ, Borges commented that "I think I'm Aristotelian, but I wish it were the other way [i.e., Platonist]. I think it's the English strain that makes me think of particular things and persons being real rather than general ideas being real." The Paris Review, 40 (1967), 162.

${ }^{25}$ Borges himself may have underestimated this difference; if so, some of his misunderstanding of Cantor's position can undoubtedly be traced to Kasner and Newman. The book is written in a popularized, colloquial style that might well make other mathematicians blanch. For example, this is their treatment of the very complex issues raised by what "existence" means in mathematics: "In modern times, the various schools of mathematical philosophy, the Logistic School, Formalists, and Intuitionists, have all disputed the somewhat less than glassy essence of mathematical being. All these disputes are beyond our ken, our scope, or our intention. A stranger company even than the tortoise, Achilles, and the arrow, have defended the existence of infinite classes. . . . A proposition which is not self-contradictory is, according to the Logistic School, a true existence statement. From this standpoint the greater part of Cantor's mathematics of the infinite is unassailable" (p. 62).

26Kline, p. 270. 
narrator, a wrecking firm owned by Zunio and Zungri finally tears down the Garay Street house. The impact of the Aleph lingers beyond the termination suggested by these "Zs," however, and the narrator in a last desperate attempt to break out of the Aleph's Strange Loop decides that the "true" Aleph is buried inside a stone pillar at the mosque of Amr where it cannot be seen, only its "busy hum" perceived. Along with the perfect futility of this final choice goes the absurdity of the narrator's desire to choose a single Aleph as the "real" one. As Borges knows, in Cantor's theory there is not one but an entire succession of Alephs, each no more or less "real" than the last. Borges's fiction implies that the Aleph, like the infinite series from which it derives its name, is a beginning without a terminus, a self-referential object capable of resisting all attempts to define or encapsulate it.

The Aleph thus provides Borges with a metaphor through which he can subvert Cantor's hope that infinity would finally be tamed and brought within the bounds of rational analysis. We have seen that the same shift in perspective that allows Cantor to treat an infinite set as a "transfinite number," seeing it as a coexisting single entity, also brought in its train paradoxes of self-referentiality that finally threw all of analysis into question. Although Borges may not be fully aware of the irony of Cantor's position within the history of mathematics, an intuitive understanding of the potential conflict permeates "The Aleph," where the scientific model is playfully represented through a fictional creation. For Borges, the science is as much a fiction as Daneri's poem, or indeed as the story itself.

I have been suggesting that Borges's response to the field concept is essentially subversive, aimed at revealing the "crevasses of unreason" that make manifest the fictionality of the concept and, by implication, of the holistic reality it tries to express. But Borges, speaking from within that world view, finds his own utterance drawn into question by his subversive strategies. To speak is to engage in sequential analysis and expression, and hence to contradict the simultaneity that is essential for Borges's paradoxes to emerge. Borges fully recognizes this limitation, as the companion essays of "New Refutation of Time" demonstrate. These essays explore the strategy of subversion not merely as an arbitrary or idiosyncratic response, but as a necessary consequence of the field concept that finally subverts the subverter.

In "New Refutation of Time" Borges turns from the possibilities that 
infinite series have for space to the implications they have for time. He wishes to show that the conclusions of Berkeley and Hume may be extended to deny time. According to Borges, Berkeley denies that there is an object existing independently of our perception of it; Hume denies that there is a subject perceiving the object. With "man" merely a collection of sensations, Borges asks whether a single repeated perception is not enough to deny time also. If the number of human experiences is not infinite, then it follows that perceptions will be repeated, either in one man's life or in the experience of two different men. The repetition has the effect of destroying time as a linear sequence and hence, if time is thought of as a series, of refuting time.

In a now-familiar ploy, Borges makes an almost imperceptible shift from "continuity" to "series" when he talks of time's flow. Borges first refers to the "continuity that is time"; but later he shifts to the "series" of time, as in the following passage: "The metaphysics of idealism declare that it is risky and futile to add a material substance (the object) and a spiritual substance (the subject) to those perceptions. I maintain that it is not less illogical to think that they are terms of a series whose beginning is as inconceivable as its end" (OI, p. 176). Though the thrust of the passage is to say that the temporal series is "illogical," its covert effect is to postulate that time is indeed a series rather than a continuity, a series "whose beginning is as inconceivable as its end." Having posited time as a series, Borges then attempts to show that the series is invalid, because perceptions-that is, terms within the series-are repeated. "Is a single repeated term enough to disrupt and confound the series of time?" Borges asks (OI, p. 178).

In the second essay, the language returns insistently to the terminology of series. Borges instances Chuang Tzu who dreamed he was a butterfly and, awakening, did not know if he was a man who dreamt he was a butterfly or a butterfly dreaming he was a man. Borges maintains that at the moment of awakening, "only the colors of the dream and the certainty of being a butterfly existed. It existed as a momentary term of the 'bundle or collection of different perceptions' which was, some four centuries before Christ, the mind of Chuang Tzu; they existed as term $n$ of an infinite temporal series, between $\mathrm{n}+\mathrm{I}$ and $\mathrm{N}-\mathrm{I}$ " (OI, p. 184). Borges argues that if, "by a not impossible chance," a disciple of Chuang Tzu had an identical dream, the series would be confounded, its progression disrupted by the unexpected repetition of terms. "Is not one single repeated term enough to disrupt and confound the history of 
the world, to tell us that there is no such history?" (OI, p. I85), he asks in words nearly identical to those of the first essay.

In order for Borges's argument to succeed, it is necessary for him to postulate time as a series. Because time is presented as an unvarying, absolute series, Borges can undermine the relations between terms by suggesting, through the common experience of déjà vu, that terms may be repeated in unexpected ways. If the relations defining the position of terms within the temporal series are invalidated, the terms become autonomous units whose arrangement is arbitrary. With time an arbitrary succession of unconnected units, man is merely the "bundle or collection of different perceptions" existing at a point along that succession. When the perceptions change, the man changes. "Identity" is an usual sense thus ceases to exist. To share a perception is to become the same person. "Are the enthusiasts who devote a lifetime to a line by Shakespeare not literally Shakespeare?" Borges asks (OI, p. I78).

From the foregoing, it appears that Borges is engaged in refuting the Newtonian idea of time. But the very terms he uses to refute it are imbued with the Newtonian world view, because, as the reader will recall, it is in the Newtonian view that time exists as a series of universal moments. Hence the attempt cannot entirely succeed, because the vocabulary of denial is also the language of affirmation. Borges, of course, recognizes the paradox. Having set up time as a series and shown how it can be disrupted, he proceeds to suggest that the series must inevitably be reconstituted.

That the return of the series is inevitable is suggested most deviously by the following passage. "I repeat," Borges says, "there is not a secret ego behind faces that governs actions and receives impressions; we are only the series of those imaginary actions and those errant impressions." "Series" in this sentence means the temporal series of mental perceptions that constitutes "man." But when Borges immediately continues by repeating the word "series," he changes its referent. "The series? If we deny spirit and matter, which are continuities, and if we deny space also, I do not know what right we have to the continuity that is time" (OI, p. 175). In this second use of "series," it does not mean temporal progression, which has now become a "continuity," but rather denotes the sequence of terms emerging from the idealist postulates of Berkeley and Hume. The word "series" in this passage acts as a pivot whose changed meanings contain an essential paradox: first "series" means temporal series, then it means the inevitable extension of 
the idealist argument. The disruption of (temporal) series is thus made to form the final term of the series proceeding from idealist premises. If the temporal series has been refuted, the series of philosophical conjectures has been extended. To deny series in one instance paradoxically creates a new series, with its implicit chronology of successive generations of philosophical argument.

The two sequential essays of "New Refutation" pose the same paradox in structural terms. The two essays largely repeat each other, confounding the expected seriality of argument by making us experience as repetition what we would ordinarily expect to be progression. "I deliberately did not combine the two into one article," Borges writes, "because I knew that the reading of two similar texts could facilitate the understanding of an indocile subject" (OI, p. 172). Reading the two essays does indeed "facilitate the understanding," by making us experience the very repetition that forms the basis for Borges's proof that temporal series can be disrupted. ${ }^{27}$ But the essays also exist as a series, as essays " $A$ " and " $B$ ". Though they are similar enough to evoke the feeling, "I have read this before," they are different enough to suggest a progression in Borges's thought in the two years separating their composition-that is to say, they exist not only as a repetition but as a progressive temporal series.

Colin Butler, in a rigorous analysis of Borges's examples, demonstrates that the same paradox is true of virtually every piece of evidence Borges adduces to prove that time does not exist. Take the case, for example, of Chuang 'Tzu. Butler writes,

so hermetic are Chuang Tzu's respective psychic states that he can never be finally certain whether he was a man who dreamed he was a butterfly, or vice versa. The fact remains, however, that he was either one or the other; and while his true identity may be questionable, that it is so can only be the consequence of an act of recollection, with its implication of change, and therefore of succession; which his example was intended to controvert. ${ }^{28}$

\footnotetext{
${ }^{27} \mathrm{Ned}$ J. Davison also points out the mimetic form of these essays in "Aesthetic Persuasion in 'A New Refutation of Time,'” Latin American Literary Review, I4 (1979), I4.

${ }^{28}$ Colin Butler, "Borges and Time: W'ith Particular Reference to 'A New Refutation of Time," Orbis Litterarum, 28 (1973), 157.
} 
Butler argues, to my mind convincingly, that Borges's essay is a "temporary revaluation [of idealist arguments] within the framework of an ontology that remains conventional throughout." 29 The real agenda for Borges's article, Butler hints, is not to extend the idealist argument to refute time, but to create a framework in which Borges can place, with maximum plausibility and effect, the intimation of eternity that he experienced on one particular summer evening in Barracas. So Butler shrewdly guesses that "A New Refutation of Time" is in fact "written backwards, and its initial philosophizing is only indirectly relevant to what comes after." 30

If we accept Butler's line of reasoning, the paradox that keeps recurring with the destruction and reconstitution of series can be seen as a result of Borges's inability fully to realize the ontological premises for which he himself argues. Borges can arrive at a felt sense of "the inconceivable word eternity" (OI, p. I80) only by momentarily suppressing the knowledge that the moment he participates in is not a unique event, but one of an almost endless series of moments, most of which are inimical or indifferent to this feeling. Butler points out that essential to the kind of personal experience Borges is describing "is its capacity to exclude . . . its credibility depends ultimately on the success with which Borges suppresses other felt states which militate against it."31 Borges's strategy in trying to attribute to the moment a unique status is to separate it out from the flow of time; and this can be done only if the continuum of time is first made into a series. Then the sequentiality of the series is denied or stopped so that the single term containing the desired moment can become omnipresent and of infinite duration.

The problem with this strategy is exactly that encountered by the narrator of "The Aleph." Once the person (or moment, or event) is conceded to form a term in a series, its existence implies the inevitability of the other terms, which will sooner or later emerge to push the favored term out of mind. The narrator confesses at the end of "The Aleph" that "I myself am distorting and losing, under the wearing away of the years, the face of Beatriz" ( $A$, p. 30$)$. But positing a series is also essential, for if the world is instead perceived as a continuum, there is

29Ibid., p. I59.

${ }^{30}$ Ibid., p. Iss.

${ }^{31}$ Ibid., p. 160. 
no possibility of separating out the chosen element to begin with. The very action that allows choice to operate also assures that the choice will be less than absolute. The circular dialectic, then, is not merely an arbitrary requirement imposed by Borges's skepticism. Rather, it is a profound recognition of Borges's part that "really, what I want to do is impossible” ( $A$, p. 27).

We can now appreciate that the same paradox was implicit from the beginning in Borges's use of transfinite set theory. Cantor's proof that the part could be as copious as the whole seemed to offer a mathematically rigorous demonstration that the single term can be made into the whole. In this case, of course, the necessity of succession is overcome because the part has supplanted the whole. But the victory is illusory, for to accept the presence of an infinite series is also to accept that there will be an entire succession of infinities, with aleph-null succeeded by aleph-one, aleph-one by aleph-two, aleph-two by alephthree ... The infinite series that allows Borges to replace the whole with the equally copious part at the same time dooms him to the succession that such a series implies. In "New Refutation," this same paradox besets Borges-the-author as it had earlier Borges-the-narrator of "The Aleph." Borges, speaking in his own voice, is forced to recognize that his intimation of eternity is also subject to the "endless series" that so distressed the narrator of "The Aleph." Thus no terminal resting place is possible, not even the apparent terminus of Borges's own skepticism.

The inherent limitations of Borges's attempt to overcome time become explicit in the last paragraph of "New Refutation." "Time is the substance I am made of," Borges comments. "Time is a river that carries me away, but I am the river; it is a tiger that mangles me, but I am the tiger; it is a fire that consumes me, but I am the fire" (OI, p. I87). We thus come, by virtue of Borges's dialectic, around again to the realization that to confirm something is to deny it, to disrupt it is to reconstitute it. The pattern is circular.

As we have seen, the general progression of Borges's argument in "New Refutation" also forms a circle: first time as a series is created; then it is disrupted; finally it is reconstituted, bringing us back to the starting point of the cycle. This recalls the circular patterns imposed on linear series in such stories as "The Circular Ruins" and "The Approach to al-Mu'tasim." But the result now is not merely the loss of the ra- 
tionality of the Newtonian world view, but the undermining of Borges's own skepticism and idealism. His strategy of claiming that there are no final answers is not final, either.

I began this chapter by comparing Borges with Nabokov and suggesting that their artistic responses to the field concept were fundamentally different. I should like to close by suggesting ways in which they are the same. We have seen that Nabokov took from the new physics the assurance that time can be reversed, placed it in the context of mirror symmetry, and then introduced some slight asymmetry that became identified with the recognition that time does, after all, proceed. Borges appropriates from Cantor set theory the idea of an infinite set as a single, pre-existing entity, and then applies the model to time in order to prove that temporal succession must yield to eternity. But like Nabokov, Borges must finally admit some limitations to his artistic project. Thus both Borges and Nabokov seek to appropriate parts of the field concept for their own purposes, and both end by admitting that the appropriation can never be complete.

The reflection suggests that Borges, like Nabokov, remains grounded in the Newtonian world of ubiquitous, omnipresent time that is finally the ultimate series to which both succumb. Borges himself knows that the series he uses to subvert the field concept involves him in paradoxes that he creates and exploits, and to which he also yields. But worse for Borges than being subject to this limitation is to be trapped within a clear-cut world where continuities of logical progression render paradox impossible. In such a world, all the artist can say is, "The world, alas, is real; I, alas, am Borges." 